\title{
Design como ilusão: além da materialidade
}

\section{Design as illusion: beyond materiality}

\author{
Camila Soares Caldeira ${ }^{[1]}$, Ana da Rosa Bandeira \\ (orientadora) $)^{[2]}$
}

\begin{abstract}
Resumo: O presente artigo introduz a discussão, sob a ótica da filosofia do design - especialmente a partir de Flusser (2007) e Forty (2007) acerca das funções do design a partir de sua (i)materialidade. Em termos metodológicos parte de uma revisão bibliográfica (GIL, 2002) que tem como objetivo primeiro apresentar a etimologia do termo. A partir daí, busca-se contextualizá-lo considerando seu caráter projetual e manipulador da matéria, problematizando com isso seu papel enquanto campo de atuação profissional na sociedade.
\end{abstract}

Palavras-chave: Design. Filosofia. Materialidade.

Abstract: This work introduces the discussion about design functions by its (im)materiality. The argumentation was done through the perspective of design philosophy studies, especially the ones from Flusser (2007) and Forty (2007). In methodological terms, it is supported by a bibliographic review (GIL, 2002) that presents the term etymology as main objective. From this, we seek to contextualize it considering the project character, as well as its material manipulator one, also discussing its professional standing in the society.

Keywords: Design. Philosophy. Materiality

\section{INTRODUÇÃo}

Dentre as dezenas de significados - e ressignificados - que a palavra design possui, vale destacar alguns como os substantivos "forma" e "desenho" e os verbos "projetar" e "simular".

[1] Graduação em Design Gráfico, UFPEL. c.soarescaldeira@gmail.com

[2] Doutorado em Comunicação e Informação, UFRGS. anaband@gmail.com 
Este termo último ("simular"), em particular, é o conceito onde se concentra e que se pretende explorar através deste artigo.

O homem desde sempre vem manipulando o ambiente em que vive, e entendendo o design como uma das ferramentas pela qual se dá essa manipulação, tal atividade se torna elo entre nós e o mundo. Partindo do pensamento dicotômico de Platão da divisão do mundo em essencial e material, o ambiente em que vivemos (material), das coisas, dos fenômenos, possui uma essência (o mundo das ideias). "Todas as coisas com as quais nos relacionamos [...] seriam apenas cópias imperfeitas dessas essências" (PORTUGAL, 2013, p.29). A ideia fundamental é: se vejo uma mesa de madeira, o que vejo é a madeira em forma de mesa. A madeira é a "matéria" e o conceito de mesa sua "essência", pois é eterna e imutável. Ao transformar madeira em mesa (design), estaríamos colocamos em contato o mundo das ideias com o mundo material, tornando o Design um deus que manipula e engana através da aparência.

Diante do exposto, o presente artigo tem como objetivo introduzir alguns conceitos do design sob a ótica da Filosofia através da revisão bibliográfica por meio de autores como Forty (2007) e Flusser (2007). Almeja-se pensá-lo além de sua natureza projetual, que possui como finalidade a materialização do objeto, mas também em sua qualidade de construção de pensamento e percepção atuando na formação do mundo e da própria realidade (inventada, construída e percebida por nós).

Pretende-se pensar o design como articulador simbólico que vai além da materialidade. Resultado do reflexo da percepção humana sobre o mundo, sendo a sua base a relação entre sujeito e objeto, isso é, sujeito e design.

\section{A FORIMA, A MATÉRIA E O IMATERIAL}

Em seu ensaio, Forma e Material, que introduz o livro Mundo Codificado (2007), Flusser busca compreender o "imaterial". Para isso, apresenta um discurso etimológico a partir da palavra "matéria". Segundo o filósofo (op.cit., p.23), a palavra seria 
resultado de uma tentativa de traduzir o termo grego hylé que significa "madeira". Porém os gregos não se referiam a qualquer madeira, mas sim àquelas estocadas nas oficinas dos carpinteiros, aludindo às ideias platônicas de "forma" e "matéria".

Para Platão, o mundo, tal qual como percebemos, é encoberto por uma ilusão. Ele existe em sua essência, em sua "forma", independente de nós. O modo como nos relacionamos com ele por meio de nossos sentidos seria o "mundo material", enquanto a "verdade", onde estão as ideias, seria o "mundo formal". "Ora Deus, ou porque não quis, ou porque era necessário que ele não fabricasse mais do que uma cama natural, confeccionou assim aquela única cama, a cama real" (PLATÃO, 2010, p.453). Portanto, os conceitos de "forma" e "matéria" se apresentam como opostos. A "forma" é o "espírito" dos objetos, a ideia eterna e imutável, pois posso imaginá-los em qualquer tempo ou espaço. A “matéria", por sua vez, é a aparência, o modo como esses objetos se apresentam.

Seguindo tal raciocínio, para Flusser (2007, p. 28), “informar" significaria então impor forma à matéria, isto é, tornar o material aparente, definindo o design em seu caráter enganador e ilusório.

\footnotetext{
Se "forma" for entendida como o oposto de "matéria", então não se pode falar de design "material"; os projetos estariam sempre voltados para informar. E se a forma for o "como" da matéria e a "matéria" for "o quê" da forma, então o design é um dos métodos de dar forma à matéria e de fazê-la aparecer como aparece, e não de outro modo. O design, como todas as expressões culturais, mostra que a matéria não aparece (é inaparente), a não ser que seja informada, e assim, uma vez informada, começa a se manifestar (a tornar-se fenômeno). A matéria no design, como qualquer outro aspecto cultural, é o modo como as formas aparecem (idem).
}

Quando falamos "gosto do design dessa mesa" ou "aquela cadeira possui um design inovador", normalmente, estamos nos referindo à aparência dos objetos e esse é um dos principais significados relacionados à palavra design: o de dar beleza e forma às coisas. Grande parte da literatura tra- 
tou o design dessa maneira, apenas como uma ferramenta de tornar os objetos belos, e ignoram sua potencialidade de ser um transformador social que vai além da simples composição dos materiais.

Expandindo tal pensamento, percebemos que a relação entre o homem e os objetos vai além da mera aparência. Os objetos refletem o modo como vivemos e pensamos o mundo. Apreendemos as coisas para serem transformadas, tornando o mundo natural em cultural (FLUSSER, 2007).

Forty busca compreender essa relação entre homem e objeto ao longo da história, criando assim uma nova história do design. Segundo o autor (FORTY, 2007, p.14), “[...] a história do design é também a história das sociedades: qualquer explicação de mudança deve apoiar-se em uma compreensão de como o design afeta os processos das economias modernas e é afetado por eles". Para sustentar seus argumentos, o historiador apresenta uma série de objetos desde os anos de 1750 até meados da década de 1980, buscando compreender como e por quê foram criados da maneira como foram e colocando o design, acima da aparência, como um transmissor de ideias.

Diferentemente do pensamento platônico que acredita na existência de um mundo ideal independentemente da nossa linguagem e experiência sensorial, os pensadores citados, buscam compreender o mundo organizado - ou codificado, como diria Flusser (2007) - condicionado à percepção humana. "Portanto, as coisas que existem nessa realidade existem, em parte, porque foram inventadas por nós" (PORTUGAL, 2013, p.26).

\section{DO IMATERIAL À INEXISTÊNCIA}

A grande quantidade de significados que podem ser associados à palavra design exprime a demasiada complexidade do termo. Analisado semanticamente, seguindo os estudos de Flusser (2007, p.181), seus significados estão associados à um contexto de astúcias e fraudes. Assim como as palavras "mecânica" e "máquina" (remetendo ao design de projetos não 
por mera coincidência), em grego mechos, caracteriza um mecanismo que tem como função enganar, servir de armadilha. Acompanhando o mesmo pensamento, o termo "técnica", em grego techné, significa arte, tendo seu conceito fundamentado nas ideias de "madeira" e "matéria" já expostas inicialmente. A madeira (hylé) é a matéria que recebe do artista, o técnico, sua forma. "[...] o artista provoca o aparecimento da forma" (op.cit., p.182). E por isso, Platão (2010) ao conceber a sua república ideal deixa de fora os artistas e poetas, pois estes desfiguram as formas e enganam os sentidos.

Não é por acaso que arte e design se fundem e se misturam nas discussões contemporâneas. A origem de ambos os termos está relacionada com "ilusão". Através do discurso etimológico de Flusser, pode-se compreender porque o design adquiriu o significado que é utilizado no discurso atual:

As palavras design, máquina, técnica, ars e Kunst estão fortemente inter-relacionados, cada um dos conceitos é impensável sem os demais, e todos eles derivam de uma mesma perspectiva existencial diante do mundo. [...] E por isso design significa aproximadamente aquele lugar em que arte e técnica (e consequentemente, pensamentos, valorativo e científico) caminham juntas, com pesos equivalentes, tornando possível uma nova forma de cultura (op. cit., p. 183 e 184).

A capacidade do design de "enganar" e fazer com que as coisas "pareçam diferentes do que são", também foram essenciais para o progresso das sociedades modernas, segundo Forty (2007). Partindo da teoria estruturalista, o autor aborda o design como um transmissor de ideias, esclarecendo isso por meio do conceito de mitos colocado por Roland Barthes. ${ }^{[3]}$ Os mitos são uma forma de discurso criada para solucionar as contradições existentes entre crenças e realidades, modificando o modo como vemos e pensamos o mundo.

[3] Ver mais em: BARTHES, Roland. Mitologias. São Paulo: Difel, 2002. Se fazem presentes desde a linguagem dos guias turísticos aos anúncios publicitários de eletrodomésticos, sendo, atualmente seus meios de transmissão suplementados pelo filme, jornal, televisão e propaganda. 
Entretanto, o que Forty (op.cit., p. 15) propõe é analisar o design como fundamental nesse processo de formação de ideias, já que "ao contrário da mídia mais ou menos efêmera, o design tem a capacidade de moldar os mitos numa forma sólida, tangível e duradoura, de tal modo que parecem ser a própria realidade".

O capitalismo para obter êxito depende de sua capacidade de inovar e vender novos produtos. Entretanto, a maioria das sociedades apresenta uma resistência às novidades, fazendo-se necessária a criação de aceitação dessas mudanças através do design com sua capacidade de alterar o modo como vemos as mercadorias. "Para os empresários, a utilização dos mitos é necessária para o sucesso comercial" (op. cit., p. 16).

As aparências dos objetos e a forma como nos relacionamos com eles são reflexo disso. Reconhecendo o design em sua potência transformadora - no seu sentido de "dar nova forma", "disfarçar", "mudar" - pode-se percebê-lo como meio essencial para o progresso social.

[...] a utilização desses mitos é necessária para o sucesso comercial. Todo produto, para ter êxito, deve incorporar as ideias que o tornarão comercializável, e a tarefa específica do design é provocar a conjunção entre essas ideias e os meios disponíveis de produção. O resultado desse processo é que os bens manufaturados encarnam inumeráveis mitos sobre o mundo, mitos que acabam parecendo tão reais quanto os produtos em que estão encarnados (idem).

Para exemplificar esse processo, o autor, inicialmente, examina o design dos primeiros aparelhos de rádio. Os aparelhos eram compostos por resistores, fios e válvulas aparentes, deixando-os com uma montagem grosseira e para terem aceitação do consumidor foram desenvolvidos novos meios de apresentá-los. O primeiro era uma caixa que alojava o aparelho e imitava a mobília tradicional, posteriormente, a solução foi escondê-lo em um móvel totalmente diferente, como em uma poltrona, e a que se tornou mais popular e ob- 
teve maior aceitação colocava o aparelho em um estojo desenhado com formas modernas atribuindo-lhe um novo status, sugerindo um mundo melhor e inovador. Cada um desses projetos demonstra como os objetos e suas aparências refletem a nossa percepção da realidade, alterando o principal aforismo do design para: a forma segue a intenção e não sua função (op.cit., p.21).

Descrever o design como uma atividade que invariavelmente disfarça ou muda a forma do que supomos ser a realidade vai na direção oposta de muitos lugares-comuns sobre o design, em particular a crença de que a aparência de um produto deve ser uma expressão direta da sua finalidade (idem).

Compreendendo esta natureza projetual do design sobre os objetos, podemos, em última instância, aplicá-lo sobre a própria realidade. Se todas as formas de relação entre o homem e o mundo se dá por meio da organização deste através de nossas linguagens (códigos), o (que consideramos) real torna-se objeto-limite do design.

(C O design determinase nesta intenção de combinar pragmática e poética, de unir a capacidade de fazer com o desejo de comunicar, cristalizando em formas a metamorfose do pensamento, captando e objectivando o que ainda não tem forma e o que está para além da forma, assumindo-se neste gesto como tomada de consciência que poderia considerarse, também, desvelamento (MOURA, 2006, p.74).

O deus Design engana a natureza por meio da técnica, transformando o natural em artificial. Ele está por trás de toda cultura e consiste em, com astúcia, nos transformar de simples mamíferos em artistas livres, fazendo com que surja um deus que, em suma, somos nós mesmos (FLUSSER, 2007). Diferentemente de Platão, já não compreendemos o mundo das ideias como divino e "verdadeiro" e sim como subjetivo e simbólico.

Assim como a retórica, o design não está ligado a uma busca da verdade. Mas, em uma perspectiva que enxerga 
o mundo como algo sem essência própria, o desinteresse pela verdade não transforma esse algo em engodo. Ao contrário, se o mundo ordenado em que vivemos só existe com base na relação entre sujeito e objeto, as atividades que se concentram nesta relação atuam no próprio cerne da existência - o lugar onde se rompem todas as certezas e taxonomias e que, por excesso de existência, fica no limbo da inexistência (PORTUGAL, 2013, p.32).

\section{CONSIDERAÇÕES FINAIS}

Por meio de uma pequena introdução à Filosofia do Design, o presente artigo expande os significados da palavra design evidenciando o seu caráter ilusório. Além de sua natureza projetual, o design se coloca como transformador social, uma vez que é resultado do modo como interpretamos o mundo. Está presente nos objetos, na comunicação, e, antes de tudo, na linguagem - a base de interpretação do olhar humano. Se o mundo, como conhecemos, existe apenas através de nossos sentidos, essa realidade é construída por nós sem que percebamos, nos colocando no papel de "deuses do design" e enganando a nós mesmos. Se para Platão precisávamos buscar a "verdade" nos aproximando das coisas em sua essência e nos distanciando dos nossos sentidos, o design não se preocupa em nos apresentar uma "verdade", e sim mostrar que é relativa, e se para cada olhar há uma "verdade", ela se torna, em última instância, inexistente.

\section{REFERÊNCIAS BIBLIOGRÁFICAS}

FLUSSER, Vilém. 0 mundo codificado: por uma filosofia do design e da comunicação. São Paulo: Cosac Naify, 2007.

FORTY, Adrian. Objetos de desejo. São

Paulo: Cosac Naify, 2007.

GIL, Antônio Carlos. Como elaborar projetos

de pesquisa. 4. ed. São Paulo: Atlas, 2002. 
MOURA, Catarina. O desígnio do design. In:

CONGRESSO SOPCOM, 4. Aveiro: Universidade da Beira Interior, 2005. Disponível em: <https:// goo.gl/feVQAr>. Acessado em: 3 dez. 2017

PLATÃO. A república. Trad. Maria Helena da Rocha Pereira.

9. ed. Lisboa: Calouste Gulbenkian, 2005. Disponível em:

<https://goo.gl/m2LGcB>. Acessado em: 1 dez. 2017.

PORTUGAL, Daniel B. Sobre sócrates e alces. In:

Mizanzuk, Ivan; Portugal, Daniel B.; Beccari, Marcos.

Existe Design?. Teresópolis, RJ: 2AB, 2013. 